\title{
0 curso de Letras-Libras na modalidade a distância: avaliação de um percurso
}

\section{Letters-Libras course In the distance learning mode: evaluations of a journey}

\begin{abstract}
Resumo:
Avaliar projetos de educação à distância implica assumir uma tarefa complexa que diz respeito a muitos sujeitos e a muitas temáticas. A avaliação alcança diferentes níveis; esta é sempre uma ação política e, por outro lado, tem uma dimensão didática, uma vez que permite (re)orientar e refletir sobre os processos em andamento. A avaliação tem a finalidade de aperfeiçoar o curso durante o seu desenvolvimento, o que significa que ela não pode se limitar apenas à elaboração de um relatório final. Neste artigo, apresentaremos os dados da avaliação realizada com os alunos surdos e não-surdos do curso de Letras Libras na modalidade a distância da Univesidade Federal de Santa Catarina (UFSC) considerando as categorias avaliativas relacionadas com: o sistema de tutoria, a plataforma do AVEA, os materiais usados e a estrutura de apoio. No geral, o curso tem uma avaliação positiva. Isto sugere que o curso pode estar fazendo um percurso que reflete a qualidade que se espera dos cursos de educação a distância.

Palavras-Chave: Avaliação. Educação a Distância. Libras. Estudantes Surdos.
\end{abstract}

\section{Abstract:}

Evaluating the programs of distance learning is a complex task, which involves many subjects and a variety of themes. The evaluation process encompasses different levels, and it is always a political action. On the other hand, it also has a pedagogic dimension once it allows one to think and to re-organize the processes that are already happening. In this sense, the evaluation has the goal to ensure the betterment of the program and its development. This means that the process of evaluation is much more than a final report. In this article, we will present evaluation data from deaf and hearing students in a program to form Brazilian Sign Language teachers. The categories evaluated by the students were: system of tutors, AVEA platform used, materials, and infrastructure of the distance campuses. In general, the vast majority of the students gave very positive evaluations about the program. This suggests that the course might be in a path that reflects quality that one expects in distance learning.

Keywords: Evaluation. Distance Learning. Brazilian Sign Language. Deaf Students.
BARBOSA, Heloiza H.; CERNY, Roseli Zen. O curso de LetrasLibras na modalidade a distância: avaliação de um percurso. Informática na Educação: teoria \& prática, Porto Alegre, v. 13, n. 1 , p. $156-166$, jan./jun. 2010

\author{
Heloiza H. Barbosa \\ Roseli Zen Cerny \\ Universidade Federal de Santa Catarina
}

\section{Introdução}

A Universidade Federal de Santa Catarina (UFSC) desenvolve o Curso de Licenciatura em Letras-Libras na modalidade a distância para alunos preferencialmente surdos. Em sua primeira edição contou com uma rede oito instituições de ensino superior conveniadas, possibilitando o oferecimento simultâneo da formação em diferentes regiões do país. São nove polos, localizados na: Universidade Federal do Amazonas, Universidade Federal do Ceará, Universidade Federal da Bahia, Universidade de Brasília, Centro Federal de Educação Tecnológica do Estado de Goiás, Universidade de São Paulo, Instituto Nacional de Educação de Surdos no Rio de Janeiro, Universidade Federal de Santa Maria e Universidade Federal de Santa Catarina. Cada instituição tem 55 alunos matriculados, com exceção do polo UFSC, que tem 60 alunos, totalizando 500 alunos. Esta formação é financiada pelo Ministério da Educação, por meio da Secretaria de Educação a Distância e da Secretaria de Educação Especial. O curso iniciou em outubro de 2006, com uma solenidade entre todos os polos participantes. Em 2008 o Curso de Licenciatura foi reeditado ofertando-se mais 450 vagas e iniciamos uma nova experiência 
com um Curso de Bacharelado em Letras Libras para 450 alunos, em 15 pólos.

A gestão do Curso é realizada numa parceria do Centro de Comunicação e Expressão (CCE) e o Centro de Ciências da Educação (CED). O CCE é responsável pela coordenação geral e o CED atua por meio da coordenação pedagógica, responsabilizando-se pela formação das equipes, a produção dos materiais e a pesquisa e avaliação. A atuação da coordenação pedagógica foi estruturada no projeto pedagógico do Curso e constitui-se numa experiência de parceria colaborativa entre os centros de ensino responsáveis pela formação dos professores de Letras e neste caso Letras-Libras. 0 presente artigo traz as reflexões do processo de avaliação das coordenadoras pedagógica e do Núcleo de Pesquisa e Avaliação.

O Curso de Letras-Libras está organizado de forma a expressar o conhecimento na Língua Brasileira de Sinais e privilegiar as formas de ensinar e aprender dos surdos. Além de assumir o desafio de traduzir essas formas de ensinar e aprender considerando a língua materna da maioria dos surdos que é a Língua de Sinais, está sendo realizado na modalidade a distância. Para possibilitar o cumprimento desse duplo desafio, é imprescindível a participação dos surdos no processo de planejamento, operacionalização e avaliação do curso.

Objetiva-se, com este curso, garantir a inclusão social de surdos na sociedade por meio da formação acadêmica, abrindo espaços para a sua inserção no mercado de trabalho. Os professores licenciados irão atuar na formação de professores e para atuar da sexta a nona séries do ensino fundamental, no ensino médio e no ensino superior. Esta formação passa pela Língua de Sinais que inclui aspectos sociais, culturais e políticos, presentes na construção e desenvolvimento do curso. Assim, os surdos atuarão nas escolas discutindo sobre a língua usada por eles e ensinando na sua língua materna. A formação destes professores acontece por meio de um ambiente virtual de aprendizagem, para o qual foi necessária a criação de ferramentas que possibilitassem disponibilizar os conteúdos em Libras, deste modo favorecendo o processo de comunicação. O curso também conta com os recursos de videoconferência, material impresso e DVD-Vídeo (CERNY; QUADROS, 2008).

Este artigo é fruto das reflexões do Núcleo de Pesquisa e Avaliação e Coordenação
Pedagógica do Curso, procurando refletir a formação dos professores de Letras-Libras a partir dos dados gerados pelos instrumentos de avaliação.

\section{Pressupostos da avaliação do curso}

$\mathrm{Na}$ avaliação do curso Letras-Libras, partimos do pressuposto que os programas de educação à distância precisam ser avaliados de modo formal, sendo a avaliação "[...] concebida como um processo participativo, autoreflexivo, crítico e emancipatório, que se desenvolve entrelaçado com as ações do projeto, permitindo reelaborá-las [...]" (CAPELLETTI, apud ALMEIDA; PRADO, 2005, p. 8). Afinal, ouvir a opinião dos alunos e das equipes envolvidas contribui sobremaneira para identificar os êxitos e dificuldades no percurso, garantindo, desta forma, a melhoria do curso em processo.

Avaliar projetos de educação à distância implica assumir uma tarefa complexa que diz respeito a muitos sujeitos e a muitas temáticas. A avaliação alcança diferentes níveis - é sempre uma ação política e, por outro lado, tem uma dimensão didática, uma vez que permite (re)orientar e refletir sobre os processos em andamento. A avaliação tem a finalidade de aperfeiçoar o curso durante o seu desenvolvimento, o que significa que ela não pode se limitar apenas à elaboração de um relatório final, mas constitui uma tarefa permanente e sistemática.

Nessa proposta, o sentido da avaliação está em focalizar problemáticas e avanços sem interferir de forma invasiva no processo. É necessário identificar com clareza todos os sujeitos envolvidos na avaliação, bem como o uso que se fará das informações obtidas. Outra decisão refere-se aos temas a serem avaliados, que não devem ser os mesmos em todos os momentos da avaliação, pois existe uma multiplicidade de variáveis que precisam ser contempladas e, de todo modo, seria inviável ao grupo responsável pela avaliação abordar todos os aspectos. A ideia, portanto, é associar a avaliação à pesquisa, respeitando os tempos e especificidades de cada uma, mas integrando uma a outra. O Núcleo de Pesquisa e Avaliação do Letras-Libras, sob a 
responsabilidade da coordenação pedagógica do Centro de Ciências da Educação, também, procura disponibilizar os dados para que pesquisadores possam aprofundar temáticas específicas em dissertações e teses, criando-se, assim, fóruns de discussão permanente sobre a modalidade e sobre o ensino e a formação de professores na área do curso. Nesse sentido, a avaliação mostra-se um processo democrático e transparente.

A proposta do Núcleo de Pesquisa e Avaliação é tornar-se um "guarda-chuva" de pesquisas sobre o curso em desenvolvimento, estimulando a pesquisa e socializando os resultados da avaliação e das pesquisas realizadas. Tal proposta caracteriza-se como um espaço participativo, que procura viabilizar a manifestação dos sujeitos envolvidos no processo. Coiçaud expressa bem esta ideia, argumentando que a avaliação na educação à distância

[...] requer um modelo participativo e democrático que construa uma trama de vozes a partir da diversidade dos grupos de destinatários e responsáveis. Desse modo, a avaliação será um ato de persuasão acerca do valor do projeto, a qual apelará à razão e à compreensão de um público personalizado. (COIÇAUD, 2001, p. 70)

Os dados das análises são apresentados e discutidos por todos os participantes do sistema, por meio de seminários de avaliação. Após a discussão dos dados, são sistematizadas as principais ideias advindas da discussão e dos relatórios, identificam-se os responsáveis pela implementação da mudança e encaminha-se o documento a todos os que têm responsabilidade na melhoria do curso.

Compreendemos que as tecnologias não garantem uma revolução na educação, mas elas podem ser propulsoras de mudança. Abrese, assim um fértil campo de investigação e produção teórica, que realimenta o aprofundamento das bases conceituais sobre tecnologias na educação, aprendizagem, currículo e ensino, trazendo subsídios para a reformulação de propostas de formação de educadores e fomentando pesquisas sobre os processos formativos (ALMEIDA, 2005, p. 5).

Trazer subsídios para a reformulação do projeto por meio da avaliação significa não "[...] engessar em modelos quantitativos de levantamento e interpretação de dados [...]" (SARAIVA, 1996, p. 2). Não se nega, contudo, a importância dos dados quantitativos em
"[...] nome de uma análise qualitativa, esvaziada de quantidades e de fatos [...]" (SARAIVA, 1996, p. 2). Nesta proposta, opta-se por um modelo de complementaridade, capaz de mapear dados da realidade, levando em conta as relações de sua estrutura com o contexto, trazendo para análise dados quantitativos e qualitativos.

Almeida destaca uma vantagem para fazer avaliação na EaD: a característica das tecnologias de informação e comunicação, que fazem o "[...] registro contínuo das interações, produções e caminhos percorridos, permitindo recuperar instantaneamente a memória de qualquer etapa do processo, analisá-la, realizar tantas atualizações quantas forem necessárias [...]" (ALMEIDA, 2003, p. 336). Este potencial dá-se por meio dos ambientes virtuais, que possibilitam uma avaliação processual e a autoavaliação.

A EaD no Brasil no ensino superior é recente e, por isso, carece de regulamentação, pesquisas e de instrumentos de avaliação que auxiliem a melhoria dos projetos em desenvolvimento. A avaliação dos cursos torna-se uma garantia para a melhoria do processo, privilegiando um olhar particular e ao mesmo tempo global em todas as etapas do desenvolvimento do currículo. Portanto, é fundamental estabelecer parâmetros que permitam avaliar a organização das equipes, os recursos didáticos e as ferramentas tecnológicas que dão suporte aos cursos e as atividades a serem executadas.

A EaD abre espaços de possibilidades educacionais que necessitam serem pensadas considerando as concepções pedagógicas que a permeiam; os instrumentos e materiais didáticos; a flexibilização e funcionalidade do ambiente virtual de ensino-aprendizagem (AVEA). Assim, são estes elementos que, quando pensados e planejados de forma cuidadosa e com investimentos técnicos, profissionais e financeiros adequados, podem garantir a qualidade na EaD e acabar com a visão preconceituosa de que esta é uma modalidade de educação fácil e de baixa qualidade.

\section{Critérios de qualidade}

De acordo com o documento de referenciais de qualidade de EaD publicado pelo MEC 
(BRASIL, 2007), os aspectos referentes as mídias e materiais didáticos, à promoção da interatividade e colaboração entre pares e à avaliação do curso estão listados como aspectos que conferem qualidade aos projetos de EaD, como explicita o texto abaixo:

Duas dimensões devem ser contempladas na proposta de avaliação: (1) a que diz respeito ao aluno e (2) a que se refere ao curso como um todo, incluindo os profissionais que nele atuam.

- Desenhar um processo contínuo de avaliação quanto:

a) à aprendizagem dos alunos

b) às práticas educacionais dos professores ou tutores;

c) ao material didático (seu aspecto científico, cultural, ético e estético, didático-pedagógico, motivacional, de adequação aos alunos e às TIC e informação utilizada, a capacidade de comunicação, dentre outros) e às ações dos centros de documentação e informação (midiatecas);

d) ao currículo (sua estrutura, organização, encadeamento lógico, relevância, contextualização, período de integralização, dentre outros);

e) ao sistema de orientação docente ou tutoria (capacidade de comunicação através de meios eficientes; de atendimento aos alunos em momentos a distância e presenciais; orientação aos estudantes; avaliação do desempenho dos alunos; avaliação de desempenho como professor; papel dos núcleos de atendimento; desenvolvimento de pesquisas e acompanhamento do estágio, quando houver);

f) à infra-estrutura material que dá suporte tecnológico, científico e instrumental ao curso;

g) ao projeto de educação à distância adotado (uma soma dos itens anteriores combinada com análise do fluxo dos alunos, tempo de integralização do curso, interação, evasão, atitudes e outros);

h) à realização de convênios e parcerias com outras instituições;

i) à meta-avaliação (um exame crítico do processo de avaliação utilizado: seja do desempenho dos alunos, seja do desenvolvimento do curso como um todo). (BRASIL, 2007, p. 13-14)
Estes possíveis indicadores de qualidade os quais atuam de forma indissociáveis - norteiam a proposta do Curso Letras-Libras na modalidade a distancia e, portanto, são os aspectos considerados no processo de avaliação do curso pelos os alunos, professores, tutores e equipes de trabalho. Neste artigo, apresentaremos os dados da avaliação realizada com os alunos do curso considerando as categorias avaliativas do curso. Mas antes de entrar nos dados avaliativos do curso Letras-Libras, discutiremos como alguns destes elementos (concepções pedagógicas que focam na interatividade, ferramentas, materiais pedagógicos, tutoria e AVEA) podem fornecer indicadores de qualidade à EaD.

\section{A concepção pedagógica do curso Letras-Libras}

Os cursos, tanto de Licenciatura em Língua Brasileira de Sinais - que atende majoritariamente alunos surdos - quanto de Bacharelado em Tradução e Interpretação em Língua Brasileira de Sinais - que atende majoritariamente alunos ouvintes que possuem fluência em LIBRAS - ambos, demonstram ter uma preocupação muito forte com a aprendizagem significativa para o aluno. Por aprendizagem significativa, o Projeto Político Pedagógico (PPP) do curso Letras-Libras apresenta a seguinte definição:

A proposta pedagógica deste Curso de Licen-
ciatura em Letras - LIBRAS ancora-se em três
importantes princípios para a formação na mo-
dalidade à distância: a interação, a cooperação
e a autonomia. A idéia é de que tais princípios
sejam considerados como meta para orientar o
percurso teórico-metodológico do Curso. Estes
princípios demarcam o referencial conceitual
para a estruturação dos objetivos, a escolha dos
conteúdos, a elaboração dos passos metodo-
lógicos das disciplinas e a construção dos ins-
trumentos de avaliação. Além de nortear a or-
ganização, o desenvolvimento e a avaliação do
processo ensino-aprendizagem, é o referencial
básico para toda a equipe multidisciplinar, en-
volvida na construção dos materiais didáticos.
(UFSC, 2006, p. 06)

Os três princípios: cooperação, autonomia e interação, são articulados porque são interdependentes. A cooperação em um projeto de Educação à Distância é entendida como con- 
dição básica para o seu funcionamento, pois a modalidade requer a ação conjunta de equipes multiprofissionais, entre estas destaca-se a necessária relação estudante/tutor/professor.

A interação é um dos princípios fundantes para os processos educativos que tenham como objetivo a construção e re-significação de conhecimentos, ou de aprendizagem significativa. Nos processos de interação consideram-se os conhecimentos e as experiências existentes como ponto de partida e os desafios propostos ou contextuais, como o possível a ser atingido. O princípio da interação por sua vez requer o reconhecimento de si e do outro na vivência do exercício da autonomia. Autonomia é essencialmente o exercício da auto-organização no movimento individual-coletivo, em que o indivíduo se reconhece como um ser em si, e reconhece o outro como um inteiramente outro. A autonomia, baseada nessa concepção, compreende o respeito às diferenças, às possibilidades e às condições de cada um, e o compartilhamento de competências e condições para responder a um desafio. As regras gerais são definidas e cumpridas individual e coletivamente, e são alteradas novamente no coletivo, sempre que se fizerem necessário pelo movimento dinâmico do processo instalado. (UFSC, 2006, p.10-11)

Visto desta forma, a aprendizagem significativa requer o envolvimento do sujeito, a colaboração entre os pares e uma centralidade no processo social de aprendizagem e não na transmissão dos conteúdos. Estes elementos que conferem valor e afirmam a natureza interativa e social de significação da aprendizagem direcionam, assim, o curso Letras-Libras para uma concepção de $\mathrm{EaD}$ na qual se privilegia a aprendizagem social em contraponto a aprendizagem isolacionista presente em modelos tradicionais de EaD. Portanto, a partir de sua concepção, o curso Letras-Libras busca um diferenciador qualitativo em comparação a outras propostas de EaD.

Como argumenta Lapa e Coelho (No prelo), a construção do conhecimento através da interação social dos alunos pode oportunizar a criação de comunidades de aprendizagem em um curso de EaD. As comunidades de aprendizagem podem ser um indicador de qualidade, pois:

As comunidades de aprendizagem trazem latente a possibilidade de se constituírem em espaços sociais construídos pelos professores e alunos envolvidos no processo de ensino-aprendizagem, que podem transcender o ensino burocrático de conteúdos, da visão bancária, e se constituírem nos espaços necessários para a transformação social almejada no ensino problematizador.

Desta forma, as comunidades de aprendizagem poderiam ser a base para o desenvolvimento da formação crítica do sujeito. Ela deveria passar, necessariamente, por um processo coletivo de troca de idéias, reflexão crítica e interação social, e que assim conduza a uma re-significação de informações e uma validação do conhecimento. Nesse processo realizado à distância, a comunidade de aprendizagem assume central importância, porque é o veículo por onde a aprendizagem acontece nesse novo ambiente. (LAPA; COELHO, no prelo, p. 4)

Lapa e Coelho (No prelo) analisaram a formação de comunidade de aprendizagem no curso Letras-Libras nas turmas de bacharelado do curso que iniciou em 2008. As autoras concluíram que apesar da disponibilidade de espaços virtuais de comunicação multidirecional e do planejamento pedagógico para incentivo da interação social nestes espaços, os alunos do curso Letras-Libras construiram um sentimento de grupo e de pertencimento, mas isto ainda não foi o suficiente para o estabelecimento inequívoco de comunidades interativas que leve a construções coletivas de sentido.

Embora os resultados do estudo de Lapa e Coelho (No prelo), não tenham demonstrado a existência de comunidades de aprendizagem dentro do curso de Bacharelado em LetrasLibras no formato EaD, é necessário cautela na interpretação dos resultados do estudo. Primeiro, porque os dados foram extraídos dentro de uma disciplina. $E$, segundo, porque a disciplina que forneceu os dados do estudo foi a primeira a ser cursada pela turma que estava iniciando.

A falta de familiarização com o uso de Tecnologias de Informação e Comunicação (TIC), com o formato do curso e com a sua dinâmica podem ter influenciado as interações ocorridas no AVEA de forma a não garantir a formação de comunidades de aprendizagem neste momento inicial do curso. Isto, portanto, não descaracteriza a formação de comunidades de aprendizagem como um indicador de qualidade nos curso de EaD. Mas, contrariamente, estabelece que a criação de possibilidades para que a aprendizagem passe por processos de significações coletivas é necessária para o de- 
senvolvimento gradativo de comunidades de aprendizagem. E, que, por este motivo, este fundamento interativo comunitário precisa estar presente no curso desde o seu iníco. Assim o foco na interatividade e na construção de comunidades de aprendizagem pode ser considerado um indicador de qualidade nos cursos de educação em EaD, pois tal compromisso demanda empenho metodológico e didático que vai além da concepção de EaD como transmissão de conteúdo que é aprendido isoladamente pelo aluno. O curso LetrasLibras tem esta concepção de aprendizagem social em EaD como um marco central em seu PPP, caminha na busca de uma formação compromissada com a qualidade.

\section{Materiais didáticos e docência no curso de Letras-Libras}

Seguindo a concepção de aprendizagem significativa ancorada nas interações sociais, a qual fundamenta o curso Letras-Libras, as TIC empregadas neste curso são usadas como ferramentas de aprendizagem e entendidas como elementos integrantes da natureza do processo de educação, independente da modalidade na qual esta educação é desenvolvida (presencial o a distância). Neste sentido, parte-se da premissa de que o conhecimento é socialmente construído e não transmitido.

Para atingir tal objetivo, o curso LetrasLibras disponibiliza diversas ferramentas que podem ser usadas de forma flexível por seus alunos. Tais como: Chat, Mural, Fórum, Vídeo Conferência e Vídeo Aula. Outras ferramentas são incorporadas ao curso por sugestões dos alunos e professores. No caso dos alunos, ao avaliarem o curso e as disciplinas cursadas, são motivados a sugerir melhorias para curso. Estas sugestões são sistematizadas pelo grupo de avaliação e pesquisa, por meio dos questionários de avaliação, e as mesmas são enviadas às coordenações que viabilizam as alterações. Esta metodologia de avaliação qualitativa propicia uma dinâmica ágil às necessidades dos alunos e ao processo de formação.

A abertura e a flexibilidade em si já garantem uma prática dialógica entre professor, professor-tutor, aluno e designers instrucionais que conferem uma qualidade formativa ao curso. O diálogo oportunizado pelos instrumentos de avaliação auxilia que o curso se mantenha em constante mudança e aprimoramento. Esta metodologia se contrapõe aos modelos de EaD ancorados na transmissão de um produto estático de fácil embalagem e comercialização.

Tanto as ferramentas quanto os materiais e atividades pedagógicas usadas no curso de Letras-Libras buscam a promoção da interatividade. Para tal, o ambiente virtual de ensino-aprendizagem (AVEA) foi construído para ser de fácil navegação e de interface amigável para os alunos surdos e não-surdos. O curso também conta com profissionais (tutores, professores e monitores) que desenvolvem atividades que privilegiam a autonomia, cooperação e colaboração e, assim, promovam a interatividade por meio das TIC.

Quando trabalhamos com a modalidade a distância, além do professor torna-se importante a presença de outros profissionais que em conjunto formam uma equipe responsável pelas ações didático-pedagógicas. Um destes profissionais é o professor-tutor - profissional que acompanha os alunos em seus respectivos pólos. Dentre suas atribuições, o professortutor tem a função de mediar a relação professor-aluno, já que o professor que planeja a disciplina geralmente está no pólo gerador.

O professor, físicamente distante, se comunica com os alunos por meio do AVEA, das aulas por videoconferência, das vídeo-aulas, do material que produz para a disciplina (texto-base, hipertexto etc.). O tutor, fisicamente presente, torna-se então o responsável por acompanhar de perto o desenvolvimento das atividades e o desempenho dos alunos, inclusive esclarecendo dúvidas sobre os conteúdos (presencialmente e virtualmente). Ou seja, os alunos estudam numa disciplina elaborada por um professor e são acompanhados e avaliados por outro: o professor-tutor. Daí a importância deste profissional ser fluente em língua de sinais, como também, ter conhecimentos especificos sobre os aspectos lingüistico-culturais dos surdos, uma vez que o professor-tutor um dos principais mediadores da aprendizagem dos alunos surdos (no caso da licenciatura), além de tratar de particularidades do processo tradutório na Libras (no caso do bacharelado). Adicionalmente, é também importante que o professor-tutor tenha formação em Letras, preferencialmente, ou na área da Edu- 
cação, a fim de lidar com os conteúdos específicos do curso. Diferentemente do ensino presencial, na educação a distância há, portanto, uma equipe que atua como professores, não só aquele que elabora a disciplina em si, mas também os tutores, os monitores e os próprios alunos que, além de agir autonomamente, interagem colaborativamente uns com os outros, construindo conhecimento. Neste contexto, os professores-tutores são também aprendizes, uma vez que as inúmeras interações estabelecidas no curso Letras-Libras favorecem tanto o crescimento pessoal quanto acadêmico de todos os envolvidos.

\section{O AVEA do curso Letras-Libras}

O Ambiente Virtual de Ensino Aprendizagem (AVEA) é um sistema que disponibiliza diversas ferramentas de comunicação e interação. $O$ objetivo é promover a aprendizagem, que pode ser crítica e interativa e, ao mesmo tempo, vinculada a um processo de ensino sistemático, organizado, intencional e tem caráter formal. A seleção dos AVEA é um momento que requer muita reflexão desde o início do processo de implantação de um curso. Pois desta seleção deriva uma série de outros aspectos do curso, tais como: elaboração de materiais didáticos de acordo com as ferramentas disponíveis, processos de avaliação da aprendizagem, sistemas de acompanhamento e tutoria e interface com os sistemas de controle acadêmico.

O AVEA do curso Letras-Libras é um espaço organizado com diversas ferramentas de comunicação e informação digital, no modo hipermídia, que possibilitam dois tipos de interação: a) síncrona (on-line, em tempo real, de forma simultânea, como videoconferência, chat, messenger, salas de bate-papo ou reunião) e; b) assíncrona (off-line, com agendamentos prévios, mas acessados no momento em que se deseja, possibilitando assim a existência de diferentes tipos de espaço-tempo, como fórum, lista de discussão, biblioteca, email).

No AVEA do curso Letras-Libras, os registros podem ser atualizados a qualquer momento. E neste ambiente há uma ampla possibilidade do uso do vídeo, pois a comunicação entre os surdos e os surdos e pro- fessores ocorre através da língua de sinais a qual é de natureza visual-espacial. Os escritos ou vídeos digitais se ampliam e ganham multiplicidade de vozes possibilitando revisão, reescrita coletiva e análise dos caminhos da discussão dos fórums, por exemplo (para mais detalhamento, ver Lapa e Coelho (No prelo). Desta forma, a mediação pedagógica através do AVEA ocorre de forma diferenciada da mediação presencial. Entretanto, é importante salientar que a interação pedagógica através do AVEA ocorre sem detrimento algum para a qualidade da formação crítica e instrumental do profissional, dado evidenciado em estudos recentes (para uma revisão destes dados ver, Almeida, 2003, Almeida et al., 2007, Moran, 2002).

\section{0 que dizem os alunos sobre 0 curso de Letras- Libras}

Dos quinze pólos que oferecem o curso Letras Libras, escolhemos uma amostra de treze pólos os quais nos forneceram dados de avaliação tanto do Bacharelado quanto da Licenciatura realizada no segundo semestre de 2008. A avaliação dos aspectos gerais do curso é composta de três blocos de perguntas sobre, tutoria, qualidade do material no AVEA, qualidade de apoio do pólo e qualidade de apoio do pólo central. Os alunos preenchem os questionários de avaliação ao final de cada semestre.

As Tabelas 1 e 2 mostram os resultados dos questionários respondidos pelos alunos do curso. Os dados da Tabela 1 mostram que 273 alunos do curso de Licenciatura em Letras Libras de nove pólos espalhados pelo Brasil responderam aos questionários de avaliação. Nos aspectos gerais, $28 \%$ das avaliações consideram o curso como excelente e $47,5 \%$ avaliam o mesmo como bom. Desta forma, mais de $70 \%$ das avaliações dos alunos de licenciatura afirmam que o curso está dentro de um padrão de bom à excelente.

Os dados da Tabela 2 mostram que 204 alunos do curso de Bacharelado em Letras Libras de nove pólos brasileiros responderam aos questionários de avaliação. Nos aspectos gerais, $29,2 \%$ das avaliações consideram o curso como excelente e $35 \%$ como bom. Perfazendo um total de mais de $60 \%$ das avalia- 
TABELA 1 - Dados de Avaliação dos Aspectos Gerais do Curso de Licenciatura em Letras Libras na Modalidade EaD em 2008

\begin{tabular}{|c|c|c|c|c|c|c|c|}
\hline PÓLO & TURMA & $\begin{array}{c}\text { NO DE ALUNOS } \\
\text { RESPON } \\
\text { DENTES }\end{array}$ & $\begin{array}{c}\text { EXCELENTE } \\
\%\end{array}$ & $\begin{array}{c}\text { BOM } \\
\%\end{array}$ & $\begin{array}{c}\text { REG. } \\
\%\end{array}$ & $\underset{\%}{\text { RUIM }}$ & $\begin{array}{c}\text { S.R. } \\
\%\end{array}$ \\
\hline UFSC & L & 27 & 14 & 56 & 24 & 5 & 1 \\
\hline UFSM & L & 47 & 35 & 50 & 13 & 2 & 0 \\
\hline UNB & L & 30 & 12 & 48 & 30 & 2 & 8 \\
\hline USP & L & 34 & 21 & 45 & 23 & 9 & 2 \\
\hline INES & L & 27 & 45 & 34 & 11 & 3 & 7 \\
\hline CEFET-GO & L & 29 & 21 & 60 & 14 & 1 & 4 \\
\hline UEPA & L & 27 & 25 & 45 & 19 & 6 & 5 \\
\hline UFES & L & 23 & 25 & 41 & 11 & 2 & 21 \\
\hline UFPE & L & 29 & 27 & 49 & 20 & 1 & 3 \\
\hline TOTAL & 9 & 273 & $\begin{array}{l}225 \\
28 \%\end{array}$ & $\begin{array}{c}428 \\
47,5 \% \\
\end{array}$ & $\begin{array}{c}165 \\
18,3 \%\end{array}$ & $\begin{array}{c}31 \\
3,4 \%\end{array}$ & $\begin{array}{c}51 \\
5,7 \%\end{array}$ \\
\hline
\end{tabular}

$\mathrm{L}=$ Lincenciatura; S.R. = Sem resposta

TABELA 2 - Dados de Avaliação dos Aspectos Gerais do Curso de Bacharelado em Letras Libras na Modalidade EaD em 2008

\begin{tabular}{|c|c|c|c|c|c|c|c|}
\hline PÓLO & TURMA & $\begin{array}{c}\text { NO DE ALUNOS } \\
\text { RESPON } \\
\text { DENTES }\end{array}$ & $\begin{array}{c}\text { EXCELENTE } \\
\%\end{array}$ & $\begin{array}{c}\mathrm{BOM} \\
\%\end{array}$ & $\begin{array}{c}\text { REG. } \\
\%\end{array}$ & $\begin{array}{c}\text { RUIM } \\
\%\end{array}$ & $\begin{array}{c}\text { S.R. } \\
\%\end{array}$ \\
\hline UFSC & B & 21 & 27 & 33 & 7 & 1 & 32 \\
\hline INES & B & 29 & 63 & 32 & 1 & 0 & 4 \\
\hline CEFET-GO & B & 16 & 10 & 50 & 16 & 1 & 23 \\
\hline UEPA & B & 26 & 29 & 27 & 6 & 2 & 36 \\
\hline UFGD & B & 17 & 7 & 53 & 9 & 0 & 31 \\
\hline UFPE & B & 22 & 42 & 45 & 11 & 2 & 0 \\
\hline UNICAMP & B & 26 & 40 & 22 & 3 & 0 & 35 \\
\hline UFPR & B & 28 & 25 & 28 & 5 & 3 & 39 \\
\hline UFRGS & B & 19 & 20 & 24 & 9 & 0 & 47 \\
\hline TOTAL & 9 & 204 & $\begin{array}{c}263 \\
29,2 \%\end{array}$ & $\begin{array}{l}314 \\
35 \%\end{array}$ & $\begin{array}{l}67 \\
7,4\end{array}$ & $\begin{array}{c}9 \\
1 \%\end{array}$ & $\begin{array}{c}247 \\
27,4 \%\end{array}$ \\
\hline
\end{tabular}

B = Bacharelado; S.R. = Sem resposta

ções dos alunos que acham que o curso está dentro de um padrão de bom a excelente. È importante mencionar que está média baixou em relação à Licenciatura devido o grande número de perguntas não respondidas (S.R.) nas turmas de bacharelado. Isto ocorreu porque os quesitos de avaliação relacionados ao intérprete de língua de sinais não se aplica ao curso de Bacharelado, uma vez que todos os alunos são ouvintes e proficientes em língua de sinais.

Esta busca pela qualidade no curso de Letras-Libras que se expressa pela sua concepção interacionista de EaD, pela arquitetura flexível e ágil do seu AVEA, pelo design inovador de seus materiais e pelo seu sistema de tutoria, é percebida pelos alunos do curso. Em suas avaliações semestrais, a grande maioria dos alunos avaliou o curso como de Bom a Excelente. Este é um resultado satisfatório haja visto o ineditismo do curso e o fato de o mesmo ser majoritariamente produzido em língua de sinais.

Como pode ser observado, os alunos do curso Letras Libras avaliam o curso positivamente. Em sua maioria, os alunos percebem o curso como atingindo suas metas de qualidade.

Além do preenchimento dos questionários - nos quais os alunos somente atribuem conceitos de Excelente à Ruim ao curso - eles também podem escrever suas críticas e su- 
gestões para a melhoria do curso. Esta parte do questionário, de base qualitativa, parece mais representativa da avaliação do aluno e de grande valor para os gestores e produtores do mesmo. Transcrevemos alguns depoimentos que ilustram a riqueza desta avaliação e a importância da mesma para o curso Letras Libras e formações similares, especialmente aquelas desenvolvidas na modalidade à distância.

É importante esclarecer que os depoimentos que serão apresentados foram escritos por alunos surdos e não-surdos do curso Letras Libras. A escrita em Português do aluno surdo tem uma certa singularidade. É importante que o leitor deste artigo saiba que: primeiro, a escrita dos alunos surdos seguem geralmente a estrutura organizacional de sua primeira língua que é a libras, portanto diferente da estrutura do português; segundo, a escrita em português é para os alunos surdos o registro escrito de sua segunda língua e para a qual o mesmo não tem acesso ao input acústico; terceiro, os alunos surdos vivem uma experiência educacional empobrecida tanto no ensino de sua primeira língua, a libras, quanto no ensino da segunda língua, o português, e esta experiência pode ter dificultado o acesso das normas gramaticais do português pelos alunos surdos. Devido a estas circunstâncias sociais e históricas, o português escrito dos alunos surdos diferencia-se do português escrito dos alunos não-surdos.

Após este breve esclarecimento, vamos aos exemplos das narrativas avaliativas:

O curso tem melhorado significativamente, mas uma pena que o atraso do material prejudicou (o do IEL nem chegou), pois pra baixar o DVD é muito pesado. Gostaria de sugerir que o texto base tivesse a interpretação para LIBRAS em arquivo único e não fragmentado como no AVEA, pois já que vamos baixar um arquivo pesado podemos baixar esses também.

$O$ atraso (e não entrega) do material prejudicou para os estudos em casa, já que para baixar o arquivo leva-se muito tempo e ocupa espaço no PC.

Disponibilizar os materiais no tempo adequado. Trabalhos em grupo para ser visualizados nos encontros presenciais, bem como os em dupla.

Seria muito interessante se este curso fosse gerido em bases não autoritárias ou ditatoriais. Existem formas mais brandas de dominação e imposição de idéias.
Os depoimentos revelam a abertura concedida aos alunos para identificarem os problemas que interferem no processo de aprendizagem, sendo estas questões prioritárias a serem consideradas pelas equipes, procurando-se garantir cotidianamente a melhoria do mesmo. No contraponto dos problemas temos a identificação dos pontos positivos, conforme o relato dos alunos abaixo:

Gostei muito da organização das atividades junto aos prazos, eu os achei muito coerente.Gostei também de ter disponibilizado no ambiente a versão das videoconferências da turma da licenciatura.

Gosto de estudar LETRAS + LIBRAS também percebi tutor preocupado todos alunos mas interessa aqui na sala tem discutir e opiniões depois tutor explica os conteúdos.

Tutora e intérprete sempre tratam bem também preocupação e distribuição muito bem para mim e meus colegas.

Tutores e intérpretes são excelente trabalho e fez maior apoio e colaboração. Alunos respeitam pelo trabalho com tutores e interação.

Dar prazo maior na entrega de atividades, não faltar DVD, que na minha opinião, é um dos materiais mais importantes, alem do texto base. $O$ curso de Letras LIibras, no geral, está sendo maravilhoso.

Muito bom todos contribuíram muito para minha aprendizagem. Conseguir esclarecer todas as minhas duvidas de grande ajuda as revisões da tutora. Todos de parabéns!

Os depoimentos dos alunos evidenciam que mesmo sendo os materiais especialmente planejados e desenvolvidos para os alunos surdos, são as pessoas que fazem a grande diferença - neste caso o professor tutor. Esta avaliação preliminar reforça a necessidade de investimento em profissionais qualificados, falantes de Libras para exercer o papel de professor tutor, pois são assim garantiremos um processo de ensino aprendizagem de qualidade.

\section{Considerações finais}

Além dos questionários de avaliação dos aspectos gerais do curso - os quais são preenchidos ao final de cada semestre - os alunos do Curso Letras Libras, tanto de Licenciatura quanto de Bacharelado, também 
são convidados a avaliarem cada disciplina do curso após a conclusão da mesma. Desta forma, todos os profissionais envolvidos na elaboração da mesma, podem ter um retorno informativo dos aspectos positivos e negativos da mesma.

Se cruzarmos as avaliações dos aspectos gerais do curso com as avaliações de cada disciplina por semestre, acreditamos que podemos ter, então, um poderoso instrumento de avaliação democrática e crítica. É possível obter a partir do cruzamento destes dados um quadro claro das estratégias e técnicas que deram resultados positivos (ou negativos) na formação do aluno. Este será o próximo passo a ser dado pela equipe de pesquisa e avaliação do curso Letras Libras da UFSC.
Diante do exposto neste artigo, os dados das avaliações dos alunos sugerem que os mesmos estão satisfeitos com o curso. Este dado é de grande importância, considerando que este é o primeiro curso de educação superior feito para alunos surdos no Brasil usando na sua integridade a língua brasileira de sinais. As avaliações positivas por parte dos alunos do curso de Letras Libras na modalidade a distância também são importantes para afirmação de uma proposta de educação comprometida com a qualidade. Pois estas avaliações refletem a ideia de que se montarmos um curso de formação que siga não somente os aspectos qualitativos listados pelo MEC, mas também uma proposta fundamentada na educação reflexiva, crítica, interativa e cooperativa.

\section{Referências}

ALMEIDA, M.E.B. de. Educação a Distância na Internet: abordagens e contribuições dos ambientes digitais de aprendizagem. Educação e Pesquisa, São Paulo, v. 29, n. 2, p. 327-340, 2003. Disponível em: <www.scielo. br/pdf/ep/v29n2/a10v29n2.pdf> Acesso em: 06 dez. 2008.

. O Relacionamento Entre Parceiros na Gestão de Projetos de Educação a Distância: desafios e perspectivas de uma ação transdisciplinar. In: CONGRESSO MUNDIAL DE TRANSDISCIPLINARIDADE, 2., 2005, Vitoria, ES. Anais. [S.I.: s.n.], 2005. 1 CD-Rom.

PRADO, M.E.B.B. A Formação de Gestores Para a Incorporação de Tecnologias na Escola: uma experiência de EaD com foco na realidade da escola, em processos interativos e atendimento em larga escala. In: BRASIL. Ministério da Educação. Referenciais de Qualidade Para Educação Superior a Distância. Brasília, 2007. Disponível em: <http://portal.mec.gov.br/sesu/arquivos/pdf/referenciaisqualidadeead.pdf> Acesso em: 06 dez. 2008.

ALMEIDA, M.E.B.; VECCHIO, R.D.; CERNY, R.Z.; KRUGER, S.E. Estratégias Para Ensinar e Aprender em Ambientes Virtuais. RENOTE: Revista Novas Tecnologias na Educação, Porto Alegre, v. 5, p. 1-10, 2007.

BRASIL. Ministério da Educação. Referenciais de Qualidade Para Educação Superior a Distância. Brasília, 2007. Disponível em: <http://portal.mec.gov.br/sesu/arquivos/pdf/referenciaisqualidadeead.pdf> Acesso em: 06 dez. 2008.

CERNY, R.Z.; QUADROS, R.M. Formação de Professores de Letras Libras: construindo o curriculo. In: SEMINÁRIO WEB CURRÍCULO PUC-SP, 1., 2008, São Paulo. Anais. São Paulo: PUC-SP, 2008. V. 1, p. 18. Tema do seminário: Integração de Tecnologias de Informação e Comunicação ao Currículo.

COIÇAUD, S. A Colaboração Institucional na Educação a Distância. In: LITWIN, E. Educação a Distância: temas para o debate de uma nova agenda educativa. Porto Alegre: Artmed, 2001. P. 53-72.

CONGRESSO INTERNACIONAL DE EDUCAÇÃO A DISTANCIA, 12., 2005, Florianópolis. Anais Eletrônicos... Florianópolis; [s.n.], 2005. Disponível em: <http://www.abed.org.br/congresso2005/por/pdf/131tca5.pdf> Acesso em: $14 \mathrm{dez} .2008$. 
LAPA, A.; COELHO, T. A Formação de Comunidades de Aprendizagem em Cursos de EAD. (No prelo)

MORAN, J.M. Pedagogia Integradora do Presencial-virtual. In: CONGRESSO INTERNACIONAL DE EDUCAÇÃO A DISTÂNCIA, 9., 2002, São Paulo. Anais Eletrônicos... São Paulo: ABED, 2002. Disponível em: <http://www. abed.org.br/congresso2002/index.html> Acesso em: 10 dez. 2008.

SARAIVA, Terezinha. Educação a Distância no Brasil: lições da história. Em Aberto, Brasília, v. 16, n. 70, p. 16-27, abr./jun. 1996.

UFSC. Projeto político pedagógico do curso de Letras Libras. Florianópolis, LANTEC, 2006.

Recebido em maio de 2009.

Aprovado para publicação em junho de 2009.

\section{Heloiza H. Barbosa}

Bolsista PRODOC. Centro de Comunicação e Expressão, Departamento de Pós-Graduação em Linguística da Universidade Federal de Santa Catarina (UFSC) - Florianópolis-SC/Brasil.

Email: heloiza@hbarbosa.org

Este trabalho contou com apoio de Bolsa PRODOC/CAPES, para a primeira autora.

Coordenadora Pedagógica dos Cursos de Licenciatura a Distância, Centro de Ciências da Educação (CED) da Universidade Federal de Santa Catarina (UFSC) - Florianópolis-SC/Brasil.

Email: rose@ced.ufsc.br 